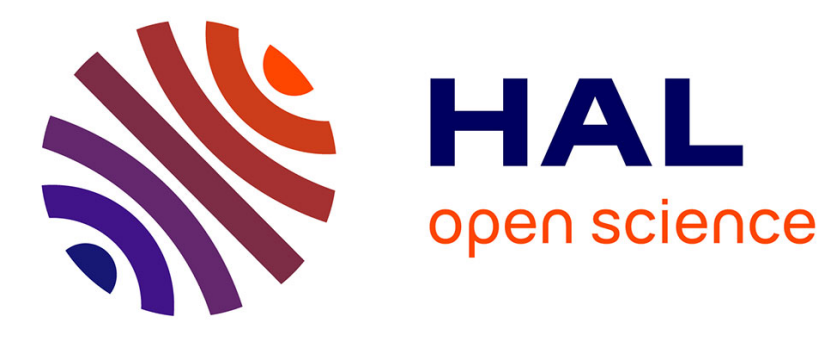

\title{
Social inequality in the prevalence of depressive disorders
}

Ingelise Andersen, Karsten Thielen, Else Nygaard, Finn Diderichsen

\section{To cite this version:}

Ingelise Andersen, Karsten Thielen, Else Nygaard, Finn Diderichsen. Social inequality in the prevalence of depressive disorders. Journal of Epidemiology and Community Health, 2009, 63 (7), pp.575n/a. 10.1136/jech.2008.082719 . hal-00477889

\section{HAL Id: hal-00477889 \\ https://hal.science/hal-00477889}

Submitted on 30 Apr 2010

HAL is a multi-disciplinary open access archive for the deposit and dissemination of scientific research documents, whether they are published or not. The documents may come from teaching and research institutions in France or abroad, or from public or private research centers.
L'archive ouverte pluridisciplinaire HAL, est destinée au dépôt et à la diffusion de documents scientifiques de niveau recherche, publiés ou non, émanant des établissements d'enseignement et de recherche français ou étrangers, des laboratoires publics ou privés. 


\section{Social inequality in the prevalence of depressive disorders}

Ingelise Andersen ${ }^{1}$ Karsten Thielen ${ }^{1}$ Else Nygaard ${ }^{1}$ Finn Diderichsen ${ }^{1}$

${ }^{1}$ Institute of Public Health Science, Copenhagen University

Centre for Health and Society

Øster Farimagsgade 5, Postbox 2099

1014 Copenhagen K, Denmark

Running title: Social inequality in the prevalence of depressive disorders

Correspondence to:

Ingelise Andersen

Institute of Public Health Science, Copenhagen University

Centre for Health and Society

Øster Farimagsgade 5, Postbox 2099

1014 Copenhagen K, Denmark

Email: inan@pubhealth.ku.dk

Phone: +4535327662

Word count: 3106

Abstract: 241

\footnotetext{
Abbreviations:

$\mathrm{ACT}=$ Anatomical Therapeutic Chemical

$\mathrm{CI}=$ Confidence Interval

DDD = Defined Daily Dose

DKK = Danish Crowns

DSM-IV $=$ Diagnostic and Statistical manual, $4^{\text {th }}$ revision

GHI = Gross household income

ISCED = International Standard Classification of Education

MDD = Major depressive disorders

MDI = Major Depression Inventory

$\mathrm{OR}=$ Odds ratio

$\mathrm{SEP}=$ socio-economic position
} 


\begin{abstract}
Background: Uncertainties exist about the strength of the relation between socio-economic position and depressive disorders. The aim of this study was to investigate the association between education, occupation, employment and income and depressive disorders measured as minor and major depression as well as antidepressant prescriptions.
\end{abstract}

Methods: Data were collected from a Danish cross sectional study collected year 2000, comprising 9254 subjects, 55\% women, and aged 36-56 years. We used register-based information on education, income and prescription.

Results: The prevalence of major depression DSM-IV algorithm was 3,3\% among men and women, whereas minor depression and prescriptions revealed statistically significant higher prevalence among females. A social gradient was found for all depressive end-points with the strongest estimates related to major depressive disorder (MDD). The associations were as follows: MDD and low education odds ratio (OR) 2.38 (CI 95\% 1.68 to 3.37), MDD and non-employment OR 11.67 (CI 95\% 8.06 to16.89), MDD and low income OR 9.78 (CI 95\% 6.49 to 14.74$)$. Education only explained a minor part of the association between nonemployment and depressive disorders and no associations were found between education and prescription. This indicates a strong two-way association between depression and nonemployment, low-income, respectively.

Conclusion: We found a social gradient in depressive disorders regardless of socio-economic position being measured by education, occupation, employment or income. Severe socioeconomic consequences of depression are indicated by the fact, that the associations with non-employment and low income were much stronger than the association with low education.

Keywords: depressive disorders, socioeconomic indicators, inequality, cross-sectional study, MDI-score 


\section{Introduction}

Depression is the leading cause of disability and is projected to become the second leading cause of the global burden of disease (DALYs) by 2020 based on a prevalence of $2.5 \%$.[1] The prevalence rates of major depressive disorder (MDD), however, are difficult to estimate. A European study showed that according to DSM-IV the lifetime prevalence of MDD was 12.8\% and 12-month (having had an episode in the past year) was 3.9\%.[2] A Canadian review found the pooled 1-year prevalence of MDD according to "assumed" DSM-IV to be $4.1 \%$, whereas life time prevalence was 6.7\%.[3] Studies reporting 1-year and lifetime sexspecific rates for MDD, consistently demonstrated rates for women that were 1.5-2.5 fold higher than for men.[2-5] However, a Danish study estimated the prevalence of MDD to be 3$4 \%$ for both sexes, whereas a statistically significant sex-difference was found only related to minor depression.[6]

Uncertainties also exist about the relation between socio-economic position (SEP) and depressive disorders. Whereas low SEP is generally associated with higher psychiatric morbidity, the association between depression and SEP has been less clear cut. In a recent meta-analysis 35 of 51 prevalence studies showed statistically significant elevated odds of depression among deprived people, whereas five studies had non-significant odds ratios below 1. The meta-analysis indicated that people in the lowest SEP (measured by different indicators) compared to the highest had increased odds ratio of prevalent MDD assessed by different types of instruments $(\mathrm{OR}=1.81, \mathrm{p}<0.001)$, the odds of incident MDD was $(\mathrm{OR}=1.24$, $\mathrm{p}=0.004$ ) whereas lower SEP individuals were much more likely to persist in depression for duration more than 1 year $(\mathrm{OR}=2.06, \mathrm{p}<0.001)$. The meta-analysis also showed that inequalities were greater for income than for education.[7] A study from the US showed that the 12-months risk of MDD among unemployed was OR 2.2 (CI 95\% 1.6 to 3.0) but among retired 0.9 (CI 95\% 0.6 to1.4).[8] The Whitehall study showed that age adjusted RII (relative index of inequality) of household income on self reported depressive symptoms (GHQ) was 2.30 (CI 95\% 1.67 to 3.17) among men and 3.36 (CI 95\% 2.04 to 5.52) among women.[9] A Danish study illustrated that prescription of antidepressant increased by age and was higher among females, low-educated, unemployed, low-income groups and singles.[10]

In general, studies on SEP and health select education, employment, occupation or income as measurement of SEP and use this one as proxy for SEP thus neglecting the others. Nonetheless, the indicators are not interchangeable. Each indicator reflects common impacts of a general social stratification in a specific society as well as different dimensions specific to each indicator.[11-15] The different indicators have causal and mediating relationships with each other. The health effect of education depends on which types of occupations are open to individuals with that type of education and the effect of occupation depends, among other things, on the income of the occupation and the individual.[16] Longterm illness are further likely to have impact on both employment and income. The assumed causal relationship between the indicators is depicted in Figure 1.

Figure 1 Pathways between socioeconomic determinants of health 
The results presented above differ in strength of the association between depression and SEP. One reason might be that the relationship between MDD and SEP has hitherto been sparsely examined in studies using comparable definitions of MDD and indicators of SEP. Consequently, the nature and underlying causes of social inequality in depression remains unclear[17,18] The use of different indicators of SEP in the same study might therefore contribute to the elucidation of the strength of the association between depression and SEP. Generally, few studies have addressed the causal relationship between the various social indicators and health.[16,19] To our best knowledge no studies have explicitly examined the confounding or mediating effect of education and income on the association between occupational group and depression. This cross-sectional study using a validated rating and register-based information on SEP as well as prescription of antidepressants aims at 1) investigating whether there is a social gradient in the prevalence of depression and 2) evaluating the role of education and income in confounding/mediating the expected effect of employment and occupation on prevalent depression.

\section{Material and methods}

\section{Study Population}

The study population is extracted from a ten percent register run by The Institute of Local Government Studies in Denmark (AKF). This longitudinal register comprises $10 \%$ of the Danish population aged 15 years and older by 1 . January 1981, N $=408000$. The Ten Percent Register has been updated annually with deaths and migrations, as well as a new cohort of 15year-olds to keep it representative of the Danish population each year. The register includes data on country and date of birth, sex, marital status, household structure, education, occupation, employment and income.

From this ten percent register was extracted a randomly selected group of adults aged 40 and 50 years, respectively, by October $1^{\text {st }}, 1999,(n=11082)$ as well as a number of persons $(n=4145)$ aged 36 to 54 years old by October $1^{\text {st }} 1999$, characterised by being unemployed for more than $70 \%$ of the time during the previous three years October 1996-1999. This group constitutes the Danish Longitudinal Study on Work, Unemployment and Health. The data included in this study is the baseline data.

\section{Data collection}

In March 2000 the extracted study population was sent a postal questionnaire comprising variables on physical and mental health, demographic and socioeconomic factors, occupational environment, social relations, health behaviours and depression. The response rate was $69 \%$ among the two cohorts of adults aged 40 and 50 years and 55\% among the cohort of long-term unemployed resulting in a study population of 9,870 subjects.[20] A total of 616 were excluded due to lack of information on depression (DSM-IV), education, occupation, employment and income, resulting in a study population including 9254 subjects, $55 \%$ women. The study population was linked to the registers with prescriptions in Statistics Denmark.

\section{Measures of socio-economic position}

The questionnaires had a high proportion of missing information on education and income. Information on education and income for each study participant and his or her cohabitant was therefore obtained from Registers for year 2000. Education was classified in three categories 
according to the International Standard Classification of Education (ISCED)-system (UNESCO 1997); (1) up to 10 years of education (ISCED level 0-2), (2) 11-12 years of education (ISCED level 3), (3) 13 and more years of education and (ISCED level 4-6).

\section{Employment and occupation}

Information on employment and occupation was obtained from the questionnaire, where participants had to write their position at work. Occupational groups were coded into social class I-V in accordance with the standards of the Danish National Institute of Social Research, which is similar to the British Registrar General's Classification I-V. For the sake of power the occupational group was divided into three groups according to employment. Employed were categorized into two groups as occupational group 1-3 (non-manual groups: executive managers, leading managers, and salaried employees), occupational group 4-5 (manual groups: skilled and unskilled workers). The third group called "non-employed" consists of unemployed and those outside the labour force (incl. disability pension). Self-employed, employed without specific occupation and students were categorized based on their ISCEDcoding. Those with $13+$ years of education were classified as non-manual and those with up to 12 years of education as manual.

\section{Income}

Information on gross annual income was obtained from the Register of Income Statistics for each study participant and his or her cohabitant. Household income comprises all income types subject to income taxation (wages and salaries, all types of benefits and pensions, net surplus or deficit, interest received and shared dividends). Information on cohabitation status was derived from Registers with socio-economic information in Statistics Denmark.

We calculated gross household income (GHI) as the sum of individual and cohabitants gross income. Mean GHI in Denmark year 2000 was 307300 DKK per year.[21] The rate of exchange that year was 12 DKK for 1£.[21] Initial analyses of associations between prevalence of MDD and GHI divided into deciles showed that the association between income and MDD was almost the same for people with GHI between 175000 and 450000 DKK. From these results GHI was divided into three groups: $<175000,175000-450000 \& \geq$ 450000 DKK.

\section{Other covariates}

In the analyses we further adjusted for sex, cohabitation, dichotomised as living alone or cohabiting, age as continuous variable, cohort of origin and ethnicity categorized as native born Danes, immigrants from western countries, immigrants from non-western countries.

\section{End-points - Measurement of depression}

End-point was depression defined in three different ways:

Firstly, from the survey depression was measured with the 'Major Depression Inventory' (MDI), which has been validated at clinical and population levels.[22-24] The inventory consists of 10 items, of which three are core symptoms, that cover the ICD-10 as well as the DSM-IV diagnosis of MDD. MDI assesses information on depressive symptoms with a continuous duration of at least 2 weeks. According to the DSM-IV algorithm, five of ten symptoms including at least one core symptom, has to be present. MDD is constructed by use of the algorithm and corresponds to a score $>25$ points. [22] 
Secondly, also from the survey minor depression was defined as a MDI-score $\geq 15$ to 25 points, compared to those with a score $<15$ points. Those with a score $>25$ points, equal to 372 individuals, were excluded from this analysis. We chose these cut-off points, because studies have shown, that MDI-score $<13.3$ points equals no depression,[23] and $25 \mathrm{MDI}-$ scores is very close to the DSM-IV algorithm.

Thirdly, depression was measured by means of prescription of anti-depressants. Since 1994 all prescribed antidepressants, picked up at Danish pharmacies including the date of prescription and the Defined Daily Dose (DDD), have been registered in The Medicinal Product Statistics.[25] Cases were coded according to the Anatomical Therapeutic Chemical (ATC) classification system[26] covering prescriptions of all antidepressants (ATC-code N06A). The use of antidepressants was defined as the dispensing of more than 179 DDD of any combination of different antidepressant, which approximately indicates a continuous treatment, for at least six months. We used information for year 2000.

\section{Statistical modelling}

Odds ratios with $95 \%$ confidence intervals $(95 \% \mathrm{CI})$ were calculated using logistic regression modelling. We initially analysed the effect of age by including age as a continuous as well as a squared variable. Also, initially, analyses were carried out separately for women and men. In a second series of models, the covariates sex, age, ethnicity, cohort of investigation and cohabitation were included as potential confounders. In a third series of models, we further adjusted for one and two indicators of SEP. All covariates were tested for an interaction with SEP and depressive disorders by means of the likelihood ratio test. We found no interaction defined as departure from multiplicativity, neither in the pooled data, nor in sex stratified analyses. The only exception was between sex and employment and income, respectively, on minor depression. (Likelihood-ratio test for interaction between sex and employment, $\mathrm{p}=0.003$, between sex and income, $\mathrm{p}=0.006$ ) According to the Bonferroni test the result is insignificant. Consequently, since the associations were similar for men and women we did not stratify the analyses by sex. Statistical analyses were performed using STATA for Windows version 9.1.[27]

\section{Results}

The study population was, as shown in table 1, characterized by inequalities in unadjusted prevalence of depression according to education, occupation and employment, income, cohabitation and ethnicity. Patterns were similar for both sexes and regardless of depression being measured by DSM-IV algorithm, minor depression or antidepressants. The exception was the absence of a gradient across education on prescription. For MDD the prevalence was $3.3 \%$ among both men and women, whereas a sex-difference was seen for minor depression with $6.5 \%$ among men and $8.1 \%$ among women $(\mathrm{p}=0.004)$ and for antidepressants with a prevalence of $1.9 \%$ among men and $3.7 \%$ among women $(\mathrm{p}<0.001)$. 
Table 1 Baseline characteristics of 4137 men and 5117 women in the Danish Longitudinal Study on Work, Unemployment and Health. Prevalence data

\begin{tabular}{|c|c|c|c|c|c|c|c|c|}
\hline & \multicolumn{4}{|c|}{ Males } & \multicolumn{4}{|c|}{ Females } \\
\hline & $\mathrm{N}=$ & MDD from & MDI 15-25 & Antidepressan & $\mathrm{N}=$ & MDD from & MDI 15-25 & Antidepressan \\
\hline & 4137 & DSM-IV & points & $\mathrm{t}, \Sigma \mathrm{DDD}>6$ & 5117 & DSM-IV & Points & $\mathrm{t}, \Sigma \mathrm{DDD}>6$ \\
\hline & & algorithm & & months & & algorithm & & month \\
\hline & & $\%$ & $\%$ & $\%$ & & $\%$ & $\%$ & $\%$ \\
\hline \multicolumn{9}{|l|}{ Employment £ } \\
\hline Occupation grp 1-3 & 1917 & 1.0 & 3.0 & 1.3 & 1942 & 1.0 & 4.2 & 2.6 \\
\hline Occupation grp 4-5 & 1534 & 2.0 & 4.6 & 231.5 & 2007 & 1.6 & 6.9 & 2.7 \\
\hline Non-employed & 686 & 12.4 & 22.5 & 334.8 & 1168 & 10.4 & 17.6 & 7.3 \\
\hline Totally & 4137 & 3.3 & 6.5 & 801.9 & 5117 & 3.4 & 8.1 & 3.7 \\
\hline \multicolumn{9}{|l|}{ Education } \\
\hline Isced $\geq 13$ yrs & 926 & 2.5 & 3.3 & 2.3 & 1228 & 1.8 & 4.7 & 3.8 \\
\hline Isced $11-12$ yrs & 2188 & 2.5 & 6.0 & 1.6 & 2433 & 2.9 & 7.4 & 3.5 \\
\hline Isced $\leq 10$ yrs & 1023 & 5.6 & 10.6 & 2.4 & 1456 & 5.5 & 12.2 & 4.1 \\
\hline \multicolumn{9}{|c|}{ Gross household yearly income } \\
\hline$>450000 \mathrm{DKK}$ & 2212 & 1.2 & 2.8 & 1.3 & 2600 & 1.1 & 5.4 & 2.6 \\
\hline 175-450 000 DKK & 1507 & 3.7 & 9.0 & 2.2 & 1990 & 4.6 & 9.2 & 4.2 \\
\hline$\leq 175.000 \mathrm{DKK}$ & 418 & 12.7 & 19.0 & 4.3 & 527 & 9.7 & 18.5 & 7.4 \\
\hline \multicolumn{9}{|l|}{ Cohabitation } \\
\hline Cohabiting & 2795 & 2.4 & 4.9 & 1.6 & 3502 & 2.5 & 6.9 & 3.4 \\
\hline Living alone & 1342 & 5.1 & 9.9 & 2.6 & 1615 & 5.3 & 10.7 & 4.4 \\
\hline \multicolumn{9}{|l|}{ Ethnicity } \\
\hline Danes & 3823 & 2.9 & 5.6 & 2.0 & 4824 & 3.2 & 7.8 & 3.8 \\
\hline $\begin{array}{l}\text { Immigrant from } \\
\text { western countries }\end{array}$ & 125 & 4.0 & 11.5 & 0.0 & 175 & 3.4 & 5.4 & 1.7 \\
\hline $\begin{array}{l}\text { Immigrants from } \\
\text { non-western } \\
\text { countries }\end{array}$ & 189 & 9.5 & 22.9 & 2.7 & 118 & 12 & 24 & 2.5 \\
\hline
\end{tabular}


DDD $=$ Defined Daily Dose, DKK $=$ Danish Crowns DSM-IV $=$ Diagnostic and Statistical manual, $4^{\text {th }}$ revision ISCED $=$ International Standard Classification of Education, MDD = Major depressive disorders, MDI = Major Depression Inventory 
Table 2 showed a statistically significant social gradient in the prevalence of depression, adjusted for sex, age, ethnicity, marital status and cohort, according to education, occupation, non-employment and income. The pattern was similar for the three outcomes with the strongest association related to non-employment and income. In model a) it was shown that the strong association with employment and income persist even after adjusting for the confounding effect of education. In model b) it was indicated that the potential effect of education on the other hand partly is mediated through employment. Model c) illustrated that in the fully adjusted model among people with MDD the associations decreased considerably for education, but not for non-employed and low income people, indicating that depression also has a potential effect on non-employment and low income. The pattern was similar, but less pronounced among people with minor depression and prescriptions. Regarding antidepressant prescription the social gradient in education was significantly reversed in the fully adjusted model. 
Table 2 Odds ratios (OR) and 95\% CI of major and minor depression and anti-depressive prescriptions by SEP measured by education, employment and income, respectively, in the Danish Longitudinal Study on Work, Unemployment and Health

\begin{tabular}{|c|c|c|c|c|c|c|c|c|}
\hline & \multicolumn{8}{|c|}{ Major Depressive Disorder defined by Major Depression Inventory, DSM-IV algorithm } \\
\hline & \multicolumn{2}{|c|}{ Simple model* } & \multicolumn{2}{|c|}{ Multivariate $^{\text {a }}$} & \multicolumn{2}{|c|}{ Multivariate ${ }^{\mathrm{b}}$} & \multicolumn{2}{|c|}{ Multivariate $^{\mathrm{c}}$} \\
\hline & OR & $(95 \% \mathrm{CI})$ & OR & $(95 \% \mathrm{CI})$ & OR & $(95 \% \mathrm{CI})$ & OR & $(95 \% \mathrm{CI})$ \\
\hline \multicolumn{9}{|l|}{ Education } \\
\hline Isced $\geq 13$ yrs & 1 & & & & 1 & & 1 & \\
\hline Isced 11-12 yrs & 1.26 & $0.88-1.78$ & & & 0.86 & $0.59-1.26$ & 0.84 & $0.58-1.23$ \\
\hline Isced $\leq 10$ yrs & 2.38 & $1.68-3.37$ & & & 1.27 & $0.87-1.86$ & 1.16 & $0.79-1.70$ \\
\hline \multicolumn{9}{|l|}{ Employment $\mathfrak{£}$} \\
\hline Occupation grp 1-3 & 1 & & 1 & & & & 1 & \\
\hline Occupation grp 4-5 & 1.69 & $1.13-2.52$ & 1.64 & $1.06-2.53$ & & & 1.41 & $0.91-2.19$ \\
\hline Non-employed & 11.67 & $8.06-16.89$ & 10.89 & $7.33-16.21$ & & & 7.56 & 4.97-11.49 \\
\hline \multicolumn{9}{|c|}{ Gross household income pr year. DKK } \\
\hline$>450000$ & 1 & & 1 & & & & 1 & \\
\hline $175-450000$ & 3.48 & $2.51-4.83$ & 3.16 & $2.26-4.40$ & & & 2.10 & $1.48-2.96$ \\
\hline$\leq 175000$ & 9.78 & $6.49-14.74$ & 8.45 & $5.56-12.84$ & & & 2.92 & $1.86-4.58$ \\
\hline \multicolumn{9}{|c|}{ Minor depression defined by MDI-scale point 15-25 } \\
\hline \multicolumn{9}{|c|}{${ }^{-6}$} \\
\hline Isced $\geq 13$ yrs & 1 & & & & 1 & & 1 & \\
\hline Isced 11-12 yrs & 1.64 & $1.28-2.11$ & & & 1.33 & $1.02-1.75$ & 1.32 & $1.01-1.74$ \\
\hline Isced $\leq 10$ yrs & 2.72 & $2.11-3.51$ & & & 1.92 & $1.44-2.55$ & 1.83 & $1.37-2.43$ \\
\hline \multicolumn{9}{|l|}{ Employment $£$} \\
\hline Occupation grp 1-3 & 1 & & 1 & & & & 1 & \\
\hline Occupation grp 4-5 & 1.57 & $1.26-1.97$ & 1.28 & $1.00-1.64$ & & & 1.20 & $0.94-1.54$ \\
\hline Non-employed & 5.43 & $4.29-6.87$ & 4.40 & $3.42-5.66$ & & & 3.64 & $2.78-4.74$ \\
\hline \multicolumn{9}{|c|}{ Gross household income pr year. DKK } \\
\hline$>450000$ & 1 & & 1 & & & & 1 & \\
\hline $175-450000$ & 1.97 & $1.61-2.41$ & 1.73 & $1.41-2.12$ & & & 1.43 & $1.16-1.76$ \\
\hline$\leq 175000$ & 4.17 & $3.14-5.54$ & 3.53 & $2.65-4.69$ & & & 1.89 & $1.38-2.57$ \\
\hline
\end{tabular}




\section{Prescriptions of Anti-depressants, $\Sigma$ DDD > 6 months}

\section{Education}

Isced $\geq 13$ yr

1

Isced $\leq 10$ yrs

1

$0.61-1.12$

$\begin{array}{ll}0.83 & 0.61-1.12 \\ 1.02 & 0.74-1.43\end{array}$

1

Employment $\mathfrak{E}$

Occupation grp 1-3

Occupation grp 4-5 1.15

$4.74-1.43$

Gross household income pr year. DKK

\section{$>450000$}

$175-450000$

1

$\leq 175000$

$1.77 \quad 1.32-2.37$

3.81

2.49-5.83

$\begin{array}{ll}1.47 & 1.01-2.13 \\ 4.74 & 3.29-6.83\end{array}$

$\begin{array}{llll}0.61 & 0.43-0.87 & 0.60 & 0.41-0.87 \\ 0.64 & 0.43-0-93 & 0.60 & 0.43-0.86\end{array}$

* Odds ratios (OR) are in all analyses adjusted for sex, birth year, cohabitation, cohort and ethnicity

a Adjusted for education

b Adjusted for employment

c Adjusted for education + employment + income

$£$ Occupational group 1-3 (non-manual groups: executive managers, leading managers, and salaried employees), occupational group 4-5 (manual groups: skilled and unskilled workers).

DDD $=$ Defined Daily Dose, DKK $=$ Danish Crowns, DSM-IV $=$ Diagnostic and Statistical manual, $4^{\text {th }}$ revision, ISCED $=$ International Standard

Classification of Education, MDD = Major depressive disorders, MDI = Major Depression Inventory 
As pointed out in table 3 the OR of depression was almost similar for manual versus non-manual employees independent of the cut-off point on the MDI-scale, whereas among non-employed people the relative estimates increased with severity of depression. This indicates that the two-way causal relationship between employment and depression not only exists for the occurrence of depression, but that the association is particularly strong with severe depression.

Table 3. Odds ratios (OR) and $95 \% \mathrm{CI}$ of depression at different cut-off points at the MDI scale by employment in the Danish Longitudinal Study on Work, Unemployment and Health.

\begin{tabular}{llllrl}
\hline & \multicolumn{2}{l}{$\begin{array}{l}\text { Occupational } \\
\text { group 1-3 } £\end{array}$} & \multicolumn{2}{l}{ Occupational group 4-5 } & \multicolumn{2}{l}{ Non-employed } \\
\cline { 2 - 6 } & & OR* & $(95 \% \mathrm{CI})$ & OR & $(95 \% \mathrm{CI})$ \\
\cline { 2 - 6 } MDI-scale 15-20 & 1 & 1.59 & $1.21-2.08$ & 4.83 & $3.63-6.44$ \\
MDI-scale 15-25 & 1 & 1.57 & $1.26-1.97$ & 5.43 & $4.29-6.87$ \\
MDI-scale 15+ & 1 & 1.64 & $1.35-1.99$ & 7.72 & $6.35-9.41$ \\
MDI-scale 20+ & 1 & 1.65 & $1.28-2.12$ & 8.89 & $6.96-11.36$ \\
DSM-IV & 1 & 1.69 & $1.13-2.52$ & 11.67 & $8.06-16.90$ \\
MDI-scale 25+ & 1 & 1.80 & $1.28-2.53$ & 11.74 & $8.52-16.19$ \\
MDI-scale 30+ & 1 & 1.91 & $1.18-3.10$ & 14.53 & $9.34-22.60$ \\
\hline
\end{tabular}

- All analyses are adjusted for sex, birth year, cohabitation, cohort and ethnicity

£ Occupational group 1-3 (non-manual groups: executive managers, leading managers, and salaried employees), occupational group 4-5 (manual groups: skilled and unskilled workers).

DSM-IV = Diagnostic and Statistical manual, $4^{\text {th }}$ revision, $\mathrm{MDD}=$ Major depressive disorders, $\mathrm{MDI}=$ Major Depression Inventory 


\section{Discussion}

Our results showed that the 2-week point prevalence of MDD was 3.3\% for both sexes, whereas minor depression and prescriptions revealed statistically significant higher prevalence among females. We found a social gradient in depressive disorder whichever the social indicator was education, occupation, employment or income. The association with nonemployment and income was much stronger than the association with education, and the association with occupation was particularly weak. If we assume that a strong association indicates depression both as a cause and an effect of SEP, then the stronger association with non-employment and income indicates that depression not only is caused by but also causes non-employment and low-income

\section{Comparisons to other results}

Our prevalence is in accordance with another Danish study showing a a prevalence of MDD at 3\%.[22] Contrary to studies outside Denmark we only found a sex-difference related to minor depression and anti-depressants. Part of the reason for this might be that our measure of MDD is self-reported and from a population survey and thus less influenced by sexdifferences in health care utilisation and clinical judgement.[6] The prevalence rates of minor depression were statistically significantly higher among employed women, compared to employed men $(\mathrm{p}<0.001)$, but among unemployed the prevalence was higher among men compared to women, but statistically insignificant $(\mathrm{p}=0.02)$. Whether this indicates that men are more susceptible to non-employment needs some further studies.

Since the social gradient in depression has hitherto been controversial we carefully studied the association between different indicators of SEP and three definitions of depression. Similar to other studies we found stronger associations related to income compared to education. $[7,8]$ These studies, however, did not adjust for the other socio-economic indicators. We found, that education only slightly confounded the associations with occupation and income, respectively. Another noteworthy point was that the association with income remained significant after adjusting for employment and education. We ran the analyses separately including only employed people. In the simple model the association between income $\leq 175000 \mathrm{DKK}$ and MDD was OR 3.03 (CI 95\% 1.21 to 7.54). After adjustment for education and occupation the result was OR 2.72 (CI 95\% 1.08 to 6.86). (Results not shown.) This fact may also indicate an effect of low income on depressive disorders, and/or that depression affects income even without measurable effects on employment. We used gross household income adjusted for cohabitation, instead of equivalised income. However, a Danish study showed that associations between income and myocardial infarction were independent of income indicator.[19]

As far as we know no other studies have compared the social gradients with different endpoints of depression. The fact that we found stronger estimates between education, nonemployment and income, respectively, and MDD compared to prescription could indicate insufficient treatment among lower SEP and could be explained by the fact that lower income people are less likely to see a specialist compared to people with higher income.[28] In the analyses where we adjusted for all social indicators the association with education was strongly reduced and significantly reversed. This is partly a result of overadjustment, since income and non-employment is also a consequence of depression. The result might also show that the use of anti-depressant among low-educated was lower than their need. Defining social inequality in depression by means of antidepressant prescriptions might therefore compared to 
the DSM-IV algorithm underestimate the social gap in prevalence due to differential misclassification.[29]

Even though the majority of antidepressants are described due to depression it has to be remembered that these drugs are also prescribed for other diseases.[30,31] A Norwegian study has shown that only a minority of patients with depression seeks treat for this,[32] which indicates that antidepressant prescriptions as a measurement of depression should be used with great caution.

The group of minor depression might contain well-treated MDD patients, since decreasing MDI- points could indicate effect of treatment. We therefore tried to exclude people receiving anti-depressants. The results (not shown) remained almost unchanged, indicating differential susceptibility to severity of depression, as also shown in table 3.

\section{Limitations}

There are, however, limitations to the study. Firstly, the study was cross-sectional, which although asking for symptoms/behaviours during the past two weeks, cannot be used to predict whether non-employment and low income, respectively, are effects of or causing depressive disorders. Secondly, our information on depressive disorders was self-reported. However, we used a well validated questionnaire, tried different cut-off points and investigated the associations with prescriptions as well. Our results remained robust regarding significance. Thirdly, selection bias cannot be excluded if the prevalence of depressive disorders is higher among high-educated non-responders compared to high-educated responders. We compared prescriptions among responders and non-responders by means of The Medicinal Product Statistics. The results showed that the prevalence of prescriptions among high-educated responders was 3.2\% compared to high-educated non-responders $2.6 \%$, $(\mathrm{p}=0.35)$ indicating that this was not the case. Likewise is it possible that participants underreport their depressive disorders. One Whitehall study comparing the GHQ with responses to a standardized psychiatric interview has shown that this was the case among lower grade men with psychiatric disorder.[33] If this is the case then our results regarding depressive disorders are underestimated.

\section{Conclusion}

This cross-sectional study, using register-based information on income as well as valid MDDpoint prevalence, found a social gradient in depressive disorder regardless of SEP being measured by education, occupation, employment or income. The association with nonemployment and income was much stronger than the association with education, and the association with occupation was particularly weak. This might indicate a strong two-way causal relationship with employment and income.

\section{What is already known}

- There is a social gradient in psychiatric morbidity.

- Uncertainties exist about the strength of the relation between socio-economic position and depressive disorders.

\section{What this study adds}

- Regardless of whether we measure depression as major depression, minor depression 


or use of anti-depressant we find a stronger association with non-employment and
income than with education. This might indicate a strong two-way causal relationship
with employment and income.
- The use of antidepressants is higher among high-educated compared to low-educated
people.
- We found no gender difference in the prevalence of major depression
- A gender difference is found in minor depression with higher prevalence among
employed women compared to employed men, but lower among non-employed
women compared to non-employed men

Funding: The Health Insurance Foundation (Sygekassernes Helsefond) [No. 2006B122]

\section{Competing interests: None}

The Corresponding Author has the right to grant on behalf of all authors and does grant on behalf of all authors, an exclusive licence (or non-exclusive for government employees) on a worldwide basis to the BMJ Publishing Group Ltd and its Licensees to permit this article (if accepted) to be published in Journal of Epidemiology and Community Health and any other BMJPGL products to exploit all subsidiary rights, as set out in our licence

\section{Reference List}

[1] WHO. Information on mental disorders management: depression. http/:www.who.int/mental health/management/depression/definition/en . 2007.

[2] Alonso J, Angermeyer MC, Bernert S, Bruffaerts R, Brugha TS, Bryson H et al. Prevalence of mental disorders in Europe: results from the European Study of the Epidemiology of Mental Disorders (ESEMeD) project. Acta Psychiatr Scand Suppl 2004;(420): 21-7.

[3] Waraich P, Goldner EM, Somers JM, Hsu L. Prevalence and incidence studies of mood disorders: a systematic review of the literature. Can J Psychiatry 2004; 49(2): 124-38.

[4] Nolen-Hoeksema S. Gender Differences in Depression. Current Directions in Psychological Science 2001; 10(5): 173-6.

[5] Blackmore ER, Stansfeld SA, Weller I, Munce S, Zagorski BM, Stewart DE. Major depressive episodes and work stress: results from a national population survey. Am J Public Health 2007; 97(11): 2088-93.

[6] Olsen LR, Mortensen EL, Bech P. Prevalence of major depression and stress indicators in the Danish general population. Acta Psychiatr Scand 2004; 109(2): 96103. 
[7] Lorant V, Deliege D, Eaton W, Robert A, Philippot P, Ansseau M. Socioeconomic inequalities in depression: a meta-analysis. Am J Epidemiol 2003; 157(2): 98-112.

[8] Kessler RC, Berglund P, Demler O, Jin R, Koretz D, Merikangas KR et al. The epidemiology of major depressive disorder: results from the National Comorbidity Survey Replication (NCS-R). JAMA 2003; 289(23): 3095-105.

[9] Martikainen P, Adda J, Ferrie JE, Davey SG, Marmot M. Effects of income and wealth on GHQ depression and poor self rated health in white collar women and men in the Whitehall II study. J Epidemiol Community Health 2003; 57(9): 718-23.

[10] Hansen DG, Sondergaard J, Vach W, Gram LF, Rosholm JU, Mortensen PB, Kragstrup J. Socio-economic inequalities in first-time use of antidepressants: a population-based study. Eur J Clin Pharmacol 2004; 60(1): 51-5.

[11] Martikainen P, Bartley M, Lahelma E. Psychosocial determinants of health in social epidemiology. Int J Epidemiol 2002; 31(6): 1091-3.

[12] Lynch J, Kaplan GA. Socioeconomic Position. In: Berkman L, Kawachi I, eds, Social Epidemiology. Oxford: OUP. 2000; 13-35.

[13] Liberatos P, Link BG, Kelsey JL. The measurement of social class in epidemiology. Epidemiol Rev 1988; 10: 87-121.

[14] Galobardes B, Shaw M, Lawlor DA, Lynch JW, Davey SG. Indicators of socioeconomic position (part 1). J Epidemiol Community Health 2006; 60(1): 7-12.

[15] Galobardes B, Shaw M, Lawlor DA, Lynch JW, Davey SG. Indicators of socioeconomic position (part 2). J Epidemiol Community Health 2006; 60(2): 95-101.

[16] Lahelma E, Martikainen P, Laaksonen M, Aittomaki A. Pathways between socioeconomic determinants of health. J Epidemiol Community Health 2004; 58(4): 327-32.

[17] Virtanen SV, Notkola V. Socioeconomic inequalities in cardiovascular mortality and the role of work: a register study of Finnish men. Int J Epidemiol 2002; 31(3): 614-21.

[18] Yngwe MA, Diderichsen F, Holland P, Burstrom B. The role of income differences in explaining social inequalities in self rated health in Sweden and Britain. J Epidemiol Community Health 2001; 55(8): 556-61.

[19] Andersen I, Gamborg M, Osler M, Prescott E, Diderichsen F. Income as mediator of the effect of occupation on the risk of myocardial infarction: does the income measurement matter? J Epidemiol Community Health 2005; 59(12): 1080-5.

[20] Christensen U, Schmidt L, Hougaard CO, Kriegbaum M, Holstein BE. Socioeconomic position and variations in coping strategies in musculoskeletal pain: a cross-sectional study of 1,287 40- and 50-year-old men and women. J Rehabil Med 2006; 38(5): 31621. 
[21] Danmarks Statistik. Statistisk tiårsoversigt [Statistical ten-year review]. Statistical tenyear review 2005, 1-208. 2005. Copenhagen, Statistics Denmark.

[22] Bech P, Rasmussen N, Olsen LR, Noerholm V, Abildgaard W. The sensitivity and specificity of the Major Depression Inventory, using the Present State Examination as the index of diagnostic validity. Journal of Affective Disorders 2001; 66(2-3): 159-64.

[23] Olsen LR, Jensen DV, Noerholm V, Martiny K, Bech P. The internal and external validity of the Major Depression Inventory in measuring severity of depressive states. Psychol Med 2003; 33(2): 351-6.

[24] Forsell Y. The Major Depression Inventory versus Schedules for Clinical Assessment in Neuropsychiatry in a population sample. Soc Psychiatry Psychiatr Epidemiol 2005; 40(3): 209-13.

[25] Danish Medicines Agency (Laegemiddelstyrelsen). Danish Products Statistics. www.laegemiddelstyrelsen.dk. 10-1-2008.

[26] WHO. Guidelines for ATC Classification and DDD Assignment. WHO Collaborating Centre for Drug Statistics, editor. http://www.whocc.no/atcddd/atcsystem.html . 14-52007. WHO Collaborating Centre for Drug Statistics Methodology.

[27] StataCorp. Stata Statistical Software: Release 9.0. College Station, TX 77845, USA: Stata Corporation. 2006.

[28] van Doorslaer E., Masseria C, Koolman X. Inequalities in access to medical care by income in developed countries. CMAJ 2006; 174(2): 177-83.

[29] Thielen K, Nygaard E, Andersen I, Rugulies R, Heinesen E, Bech P et al. Misclassification and the use of register based indicators for depression. Acta Psychiatr Scand 2008; Submitted paper.

[30] Angst J. Psychiatric diagnoses: the weak component of modern research. World Psychiatry 2007; 6(2): 94-5.

[31] Trifiro G, Barbui C, Spina E, Moretti S, Tari M, Alacqua M et al. Antidepressant drugs: prevalence, incidence and indication of use in general practice of Southern Italy during the years 2003-2004. Pharmacoepidemiol Drug Saf 2007; 16(5): 552-9.

[32] Roness A, Mykletun A, Dahl AA. Help-seeking behaviour in patients with anxiety disorder and depression. Acta Psychiatr Scand 2005; 111(1): 51-8.

[33] Stansfeld SA, Marmot MG. Social class and minor psychiatric disorder in British Civil Servants: a validated screening survey using the General Health Questionnaire. Psychol Med 1992; 22(3): 739-49. 


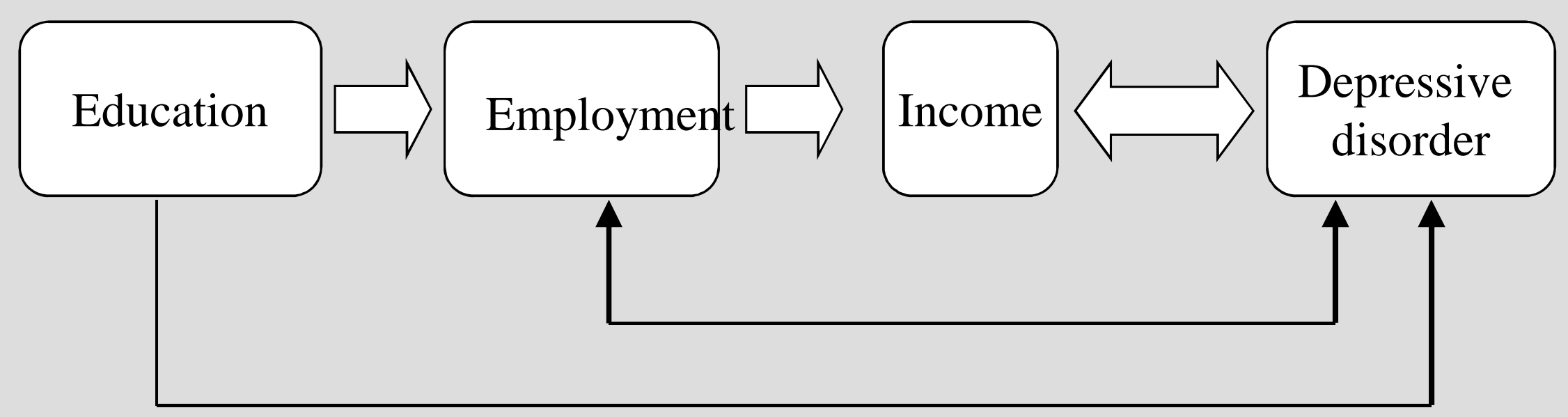

